\title{
Structure and Property of Binder-Phase of Sintered TiC-Ni Compact*
}

\author{
By Tamotsu Fukatsu**
}

\begin{abstract}
In order to obtain a better understanding of the condition of the sintering of $\mathrm{TiC}$-base cermets, the structure and property of the metal binder phase of $70 \% \mathrm{TiC}-30 \% \mathrm{Ni}$ compacts sintered at various temperatures were investigated by means of $\mathrm{X}$-ray diffraction, thermomagnetic analysis and carbon analysis. In the sintering process, $\mathrm{TiC}$ begins to diffuse into the $\mathrm{Ni}$-binder at about $800^{\circ} \mathrm{C}$, its amount increased up to $1.5 \mathrm{wt} \%$ with the increase of the sintering temperature below the eutectic temperature and about $1 \mathrm{wt} \%$ of $\mathrm{TiC}$ remained in the binder phase of the compacts sintered above the eutectic temperature. As a result of the duffusion of $\mathrm{TiC}$ into $\mathrm{Ni}$, free carbon was formed, and its amount increased up to $0.9 \mathrm{wt} \%$ in relation to the amount of $\mathrm{TiC}$ dissolved. Such free carbon was observed as graphite in the binder phase. This graphite phase is detrimental to the strength of the sintered compact, therefore it is necessary to avoid its formation. For the purpose of suppressing the graphite formation, the effect of Mo added was examined, and it was found that Mo is very suitable for this purpose.

(Received April 20, 1963)
\end{abstract}

\section{Introduction}

TiC-base cermet is well known as a superior heatand abrasive-resistant material. Also, a TiC-Ni-Mo sintered alloy has been develooed recently as an excellent cutting tool ${ }^{(1)}$. Many investigations on the fabrication of these cermets have revealed that the TiC-base cermet is more sensitive to various processing conditions than WC-base sintered compacts ${ }^{(2)}$. On the other hand, some fundamental properties have been studied on the wetting of TiC by Ni-base alloys (3) and on the phase-diagram of the ternary system of Ti-Ni$\mathrm{C}^{(4)}$. There remains, however, some problems to be clarified. One of these is the mechanism of the reaction between $\mathrm{TiC}$ and $\mathrm{Ni}$ powders during sintering. This is very important for the control of the heating or cooling rate. In the present study, changes in the structure and property of binder phase during sintering are investigated for $\mathrm{TiC}-\mathrm{Ni}$ sintered alloy by means of $\mathrm{X}$-ray diffraction, thermomagnetic analysis and chemical analysis of carbon.

\section{Experimental Procedures}

Commercial powders of $\mathrm{TiC}$ and $\mathrm{Ni}$ were used for this experiment, chemical analyses of which are shown in Table 1. The powders were used without any pretreatment. Sintered TiC-Ni compacts were prepared by the following procedures; A mixture of $70 \%$ TiC-30\% $\mathrm{Ni}$ (in weight) was ball-milled in acetone for $72 \mathrm{hr}$. After milling, the mixture was heated to evaporate the

* This paper was published originally in Japanese in the Journal of the Japan Institute of Metals, 26 (1962), 43.

** Toshiba Tungaloy Co., Tsukagoshi, Kawasaki, Japan.

(1) M. Humenik : Amer. Machinist, March, 23 (1959), 125 ; The Iron Age, March 19 (1959), 101.

(2) P. Schwarzkopf and R. Kieffer: Refractory Hard Metals, Mac Millan Co., New York, (1953), 369 ; M. Sugiyama and H. Suzuki : J. Japan Inst. Metals, 24 (1960), 618, 622, 689, $740 ; 25(1961), 1,4,8,167,321$.

(3) W. D. Kingery: J. Amer. Ceram. Soc., 36 (1953), 362 ; G. Economos and W. D. Kingery : J. Amer. Ceram. Soc., 36 (1953), 403; M. Humenik and W. D. Kingery: J. Amer. Ceram. Soc., 37 (1954), 18.

(4) E. R. Stover and J. Wulff: Trans. AIME, 215 (1959), 127. acetone, and the powders were compacted into a rectangular test block, $10 \times 30 \times 5 \mathrm{~mm}$, at $1 \mathrm{t} / \mathrm{cm}^{2}$. The green compact was sintered in a hydrogen tube furnace for $1 \mathrm{hr}$ over the temperature range of $600 \sim$ $1400^{\circ} \mathrm{C}$ at which the compact was mounted on a

Table 1 Chemical analysis and particle size of $\mathrm{TiC}$ and Ni powder used in the present experiments. TiC powder

\begin{tabular}{c|c}
\hline Total carbon & $19.3 \%$ \\
Free carbon & $<0.2 \%$ \\
Combined carbon & $19.1 \%$ \\
Fe & $0.3 \%$ \\
$\mathrm{Co}$ & $0.3 \%$ \\
\hline av. particle size & $5.1 \mu$ \\
\hline & $\mathrm{Ni}$ powder \\
$\mathrm{Ni}$ & $99.1 \%$ \\
$\mathrm{Co}$ & $0.8 \%$ \\
$\mathrm{Fe}$ & $0.035 \%$ \\
$\mathrm{Cu}$ & $0.013 \%$ \\
$\mathrm{~Pb}$ & $0.008 \%$ \\
$\mathrm{Si}$ & $0.003 \%$ \\
\hline av. particle size & $-325 \mathrm{mesh}$ \\
\hline
\end{tabular}

sintered plate of $\mathrm{MgO}$ in a graphite boat. The sintered compact was cooled in the furnace at a rate of about $10^{\circ} \mathrm{C} / \mathrm{min}$ from the sintering temperautre to $1000^{\circ} \mathrm{C}$, and the compact was brought into a cooler attached to the one end of the furnace (at $1000^{\circ} \mathrm{C}$ ) together with the graphite boat. In the case of sintering at temperatues below $1000^{\circ} \mathrm{C}$, the compact was brought into the cooler immediately after sintering.

After determining the chemical composition of the compacts by the X-ray diffraction methed, the lattice constant and Curie temperature of the binder phase in each specimen were measured to examine the effect of the sintering temperature on the structure and properties of the binder phase. In the description of these data, it is necessary to refer to the relationships 
between the lattice constant or Curie temperature and the $\mathrm{TiC}$ content of $\mathrm{Ni}$-solid solution. In this regard, Stover and Wulff ${ }^{(4)}$ reported that the lattice constant of the Ni-solid solution increased at a rate of about $0.011 \AA /$ wt \% TiC and the Curie temperature decreased with the increasing amount of $\mathrm{TiC}$ by about $70^{\circ} \mathrm{C} / \mathrm{wt}$ $\% \mathrm{TiC}$. In the present experiment these relationships were also examined with $\mathrm{Ni}$-solid solution prepared from the same powders of $\mathrm{TiC}$ and $\mathrm{Ni}$ as that of the sintered compact. The solid solution was prepared as follows; $\mathrm{Ni}$ and $\mathrm{TiC}$ powders were mixed in an agatemortar. The mixture was pressed into a compact and melted in hydrogen in an alumina crucible. The ingot was slowly cooled down to $1280^{\circ} \mathrm{C}$ and then quenched rapidly in water. Test pieces were slit from the ingots, annealed in argon atmosphere at $1200^{\circ} \mathrm{C}$ for 8 $\mathrm{hr}$, and then quenched in water. Since complete homogenization was confirmed in the specimens containing less than $3 \mathrm{wt} \% \mathrm{TiC}$, the lattice constant and Cuire temperature were determined as a function of the composition by means of metallographic observation and X-ray diffraction analysis.

As an additional test for analyzing the mechanism of reaction between $\mathrm{TiC}$ and $\mathrm{Ni}$ powders during the sintering process, the free carbon content in the sintered compacts was determined by a combustion analysis.

The Curie temperature was measured in argon atmosphere at the field strength of $45000 \mathrm{e}$ by a qualtz-spring type thermomagnetic balance. For the $\mathrm{X}$-ray technique, a conventional X-ray diffractometer with $\mathrm{CuK} \alpha$ radiation was used. Moreover, metallographic observation was made on a specimen polished by diamond powder and etched by $10 \%$ alkaline potassium ferricyanide solution.

\section{Experimental Results and Discussion}

\section{Properties of Nickel solid solution contain- ing TiC.}

In order to obtain a better understanding of the structure and properties of the metal binder phase of sintered TiC-Ni compact, the lattice constant and Curie temperature of the $\mathrm{Ni}$-solid solution were measured.

As shown in Fig. 1, the results indicated a linear increase in lattice constant with the increasing amount of $\mathrm{TiC}$ at a rate of $0.007 \AA / \mathrm{wt} \% \mathrm{TiC}$ and a linear decrease in Curie temperature at a rate of $50^{\circ} \mathrm{C} / \mathrm{wt} \%$ TiC. In Fig. 1 comparative data are also plotted for $\mathrm{Ni}$-solid solution containing $\mathrm{Ti}^{(5)(6)}$ In comparing the Ni-TiC and Ni-Ti systems, the changes in lattice constant are almost identical, but in detail the slope of the curve for the Ni-TiC system is slightly steeper than that for the Ni-Ti system $^{(\overline{5})}$ and the Curie temperature curve for the Ni-TiC system shows a slight deviation towards the upper side than that for the $\mathrm{Ni}-\mathrm{Ti}$ system $^{(6)}$.

With regard to such properties of the $\mathrm{Ni}-\mathrm{TiC}$ system, Stover et al.(4) have reported, a larger rate of

(5) W. B. Pearson: A Handbook of Lattice Spacings and Structures of Metals and Alloys, Pergamon Press, London, (1958), 791.

(6) R. M. Bozorth: Ferromagnetism, D. Van Nostrand Co., New York, (1951), 305, 325, 440. increase in lattice constant and a lower rate of decreae in Curie temperature than those in the present experiment. In the present investigation, the Curie temperature was determined by extrapolating the thermomagnetic curve to the temperature-axis where

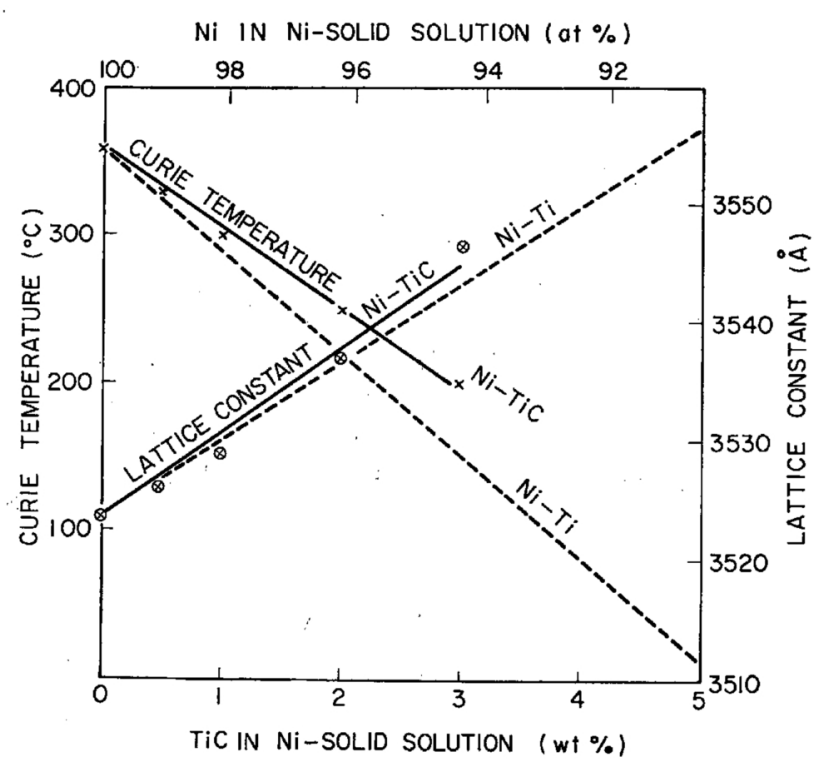

Fig. 1 Curie temperature and lattice constant of $\mathrm{Ni}$-solid solution containing $\mathrm{TiC}$.

the saturation-intensity of magnetization becomes zero. However, since Stover et al. did not describe it in detail, the difference between the two methods could not be discussed. For this investigation the relationships shown in Fig. 1 were used, as the fundamental data for the Ni-TiC solid solution.

\section{Changes in the structure and properties of the metal binder phase duriug sintering}

\section{(1) Lattice constant}

The $70 \% \mathrm{TiC}-30 \% \mathrm{Ni}$ compacts sintered at various temperatures were examined by X-ray diffraction, and all the compacts before sintering were confirmed to consist of only the two phases, $\mathrm{TiC}$ and $\mathrm{Ni}$, with no intermetallic compounds of the Ni-Ti system. Then the lattice constant and the Curie temperature of these specimens were measured. The results obtained are plotted against the sintering temperature. As shown

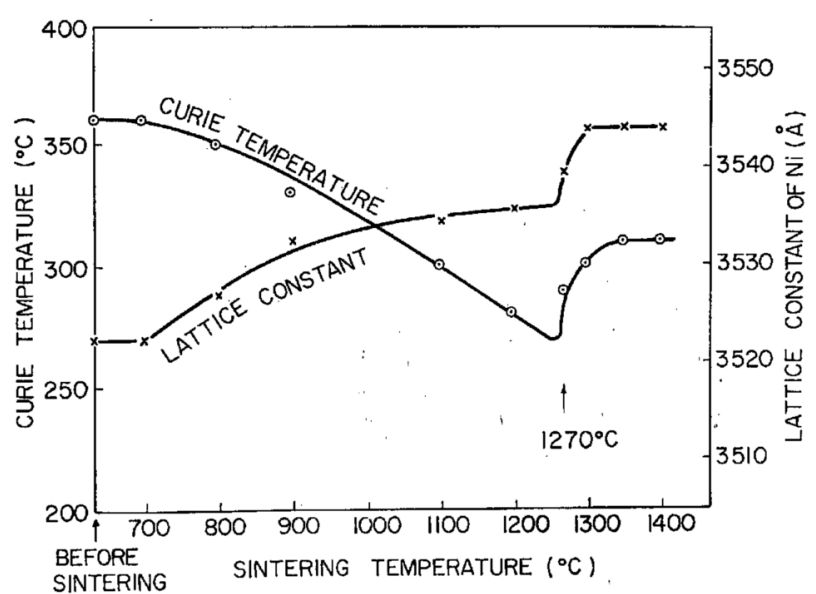

Fig. 2 Changes in lattice constant and Curie temperature of $70 \% \mathrm{TiC}-30 \% \mathrm{Ni}$ compacts sintered at various temperatures for $1 \mathrm{hr}$ in $\mathrm{H}_{2}$. 
in Fig. 2, little changes are observed in the lattice constant of the TiC-phase, but in the Ni-phase a slight increase of the lattice constant begins to appear in the specimens sintered at $700^{\circ} \mathrm{C}$, a gradual increase of the Ni lattice is seen with the increasing sintering temperature up to $1270^{\circ} \mathrm{C}$, followed by a marked increase above $1270^{\circ} \mathrm{C}$ as shown in Fig. 2.

\section{(2) Curie temperature}

Thermomagnetic cures of the specimens are illustrated in Fig. 3. As the curve of the specimen sintered at $600^{\circ} \mathrm{C}$ for $1 \mathrm{hr}$ is similar to that of the "as pressed", the Ni-binder phase is considered to be in a state of

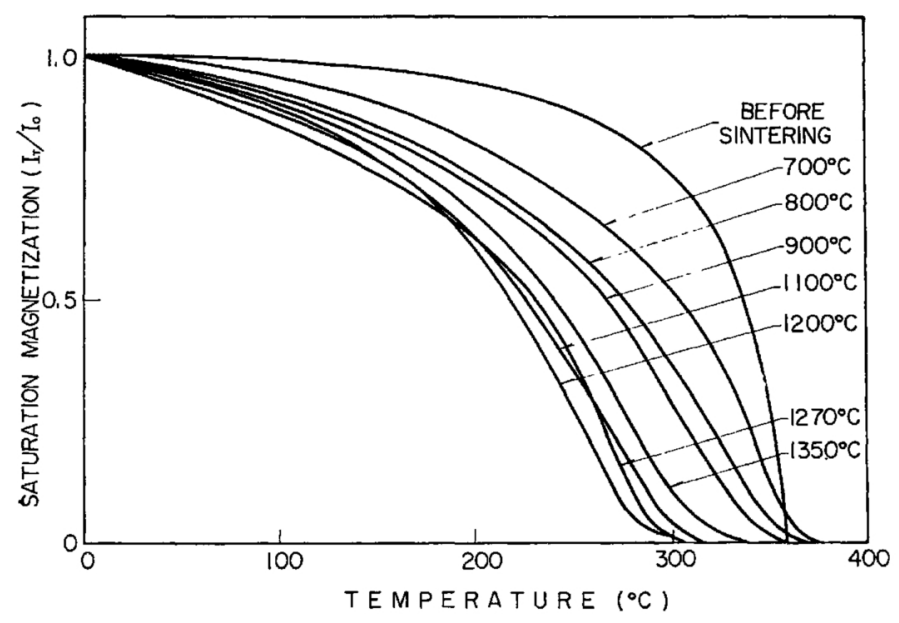

Fig. 3 Thermamagnetic curves of $70 \% \mathrm{TiC}-30 \% \mathrm{Ni}$ compacts sintered at various temperatures for $1 \mathrm{hr}$ in $\mathrm{H}_{2}$.

pure nickel. But for the specimen sintered at $700^{\circ} \mathrm{C}$ the Curie temperature is nearly the same as pure nickel, while the curve assumes a slight inward deviation. With further increase in the sintering temperature, there appears a decrease in the Curie temperature as well. However, it is observed that the deviation of the curve is reverted by sintering above $1270^{\circ} \mathrm{C}$. Curie temperatures obtained from these curves are plotted as a function of the sintering temperatures in Fig. 2 in which a discontinuous change as in the lattice constant is also observed at $1270^{\circ} \mathrm{C}$. A similar result has been observed in the WC-Co system. (7) This is probably due to the fact that a liquid phase is formed by a eutectic reaction between $\mathrm{TiC}$ - and $\mathrm{Ni}$-phases at this temperature, as evidenced by a complete microstructural densification of the compacts by sintering at a temperature above $1270^{\circ} \mathrm{C}$. The eutectic temperature of the TiC-Ni system has becn hitherto reproted to be at $1270^{\circ} \mathrm{C}^{(4)}$ or $1280^{\circ} \mathrm{C}^{(8)}$. Therefore, it can be said that the densification of TiC-Ni compact is caused by the diffusion between the solid particles in the sintering process below $1270^{\circ} \mathrm{C}$ and by the wetting of $\mathrm{TiC}$ particles with the liquid phase formed by the eutectic reaction above $1270^{\circ} \mathrm{C}$.

During the process of diffusion-sintering, the increase in lattice constant and the reduction in Curie temperature of the binder-phase were found to appear in the specimen sintered at $800^{\circ} \mathrm{C}$. This indicates the

(7) T. Fukatsu: J. Japan Soc. Powder Met., 8 (1961), 183.

(8) V.N. Eremenko: Z. Neorgan. Khin., 1 (1956), 2131 ; Ceram. Abst., (1957), 148. diffusion of $\mathrm{TiC}$ into the $\mathrm{Ni}$ binder phase at this temperature and the increases in solubility with the increasing temperature. On the other hand, in the sintering process with the liquid phase, the solubility of $\mathrm{TiC}$ in the $\mathrm{Ni}$ phase may be considered to attain a saturated value at the sintering temprature, whereas the Curie temperature of the specimen was higher than that of the specimen sintered at $1200^{\circ} \mathrm{C}$ at which diffusion-sintering took place. This can be explained as follows: $\mathrm{TiC}$ is precipitated from the $\mathrm{Ni}$ phase during cooling from the sintering temperature, but the precipitation can not occur easily in the compact sintered during the diffusion-sintering because of the poor condition in contact between particles.

Due to the changes in the lattice constant or Curie temperature as shown in Fig. 2, the solid solubility of $\mathrm{TiC}$ in the $\mathrm{Ni}$ phase increases with increase in the sintering temperature of the compacts sintered below $1270^{\circ} \mathrm{C}$ and the results of both curves coincide with each other. In the compacts sintered above $1270^{\circ} \mathrm{C}$, however, the solubility decreases discontinuously in the light of the Curie temperature, but it increases in the light of the lattice constant. This disagreement may be caused by an abnormal expansion of the Ni-lattice due to the difference in the thermal expansion coefficient between $\mathrm{TiC}$ and $\mathrm{Ni}{ }^{(9)}$ Therefore, the result deduced from the Curie temperature is more likely to hold the true situation. This experimental confirmation will be made later.

\section{(3) Analysis of free carbon}

Free carbon contents of the TiC-Ni compacts are shown in Fig. 4 as a function of the sintering temperature. It seems to increase at elevated temperatures.

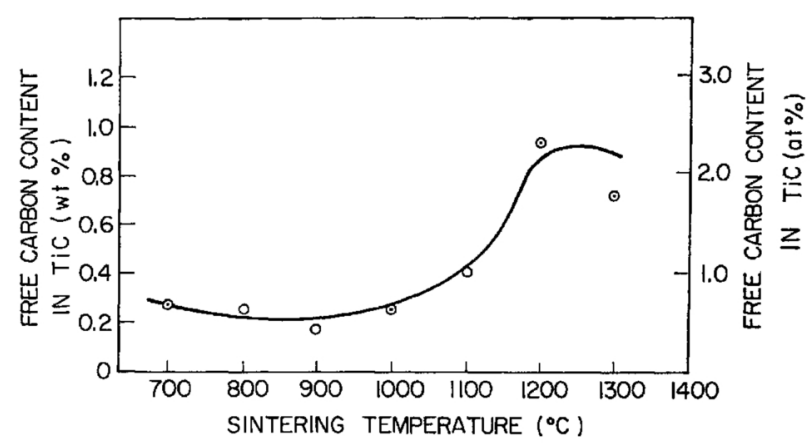

Fig. 4 Changes in the free carbon content during the sintering of $70 \% \mathrm{TiC}-30 \% \mathrm{Ni}$ compact for $1 \mathrm{hr}$ in $\mathrm{H}_{2}$.

For example, the free carbon content in the compact sintered at $1200^{\circ} \mathrm{C}$ is about $0.9 \mathrm{wt} \%$ which has the lowest Curie temperature of all compacts and the maximum amount of $\mathrm{TiC}$ dissolved in the $\mathrm{Ni}$ phase. In the compact sintered at $1300^{\circ} \mathrm{C}, 0.7$ wt $\%$ free carbon is observed. Since the amount of free carbon contained in the compact before sintering was about $0.2 \mathrm{wt} \%$, the increase in free carbon could be estimated $0.7 \mathrm{wt} \%$ by heating up to $1200^{\circ} \mathrm{C}$ or $0.5 \mathrm{wt} \%$ up to $1300^{\circ} \mathrm{C}$. As a result of the formation of free carbon, the graphite

(9) H. W. Newkirk and H. H. Sisler: J. Amer. Ceram. Soc., 41 (1958), 93. 
phase was precipitated in the binder phase. As an example of such a sintered compact, a microstrueture of the $70 \% \mathrm{TiC}-30 \% \mathrm{Ni}$ sintered at $1400^{\circ} \mathrm{C}$ for 1 hr is presented in Photo. 1 . The precipitation of the graphite-phase may be caused by dissociation of $\mathrm{TiC}$ during the sintering. However, free $\mathrm{Ti}$ was not found

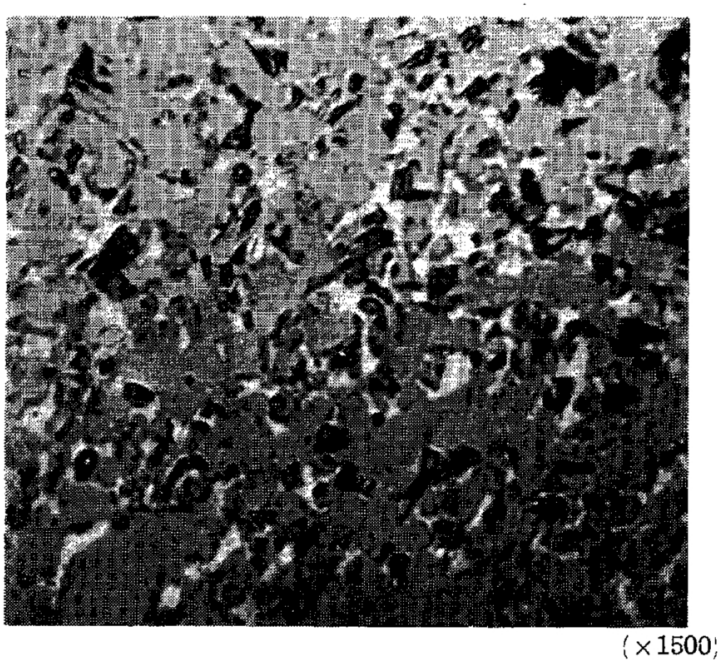

Photo. 1 Microstructure of $70 \% \mathrm{TiC}-30 \% \mathrm{Ni}$ compact sintered at $1400^{\circ} \mathrm{C}$ for $1 \mathrm{hr}$, angular gray grains are titanium carbide phase, narrow white zones are binder nickel layer and dark patches are graphite.

by the X-ray diffraction analysis. It may be said that part of the carbon content in $\mathrm{TiC}$ remains when $\mathrm{TiC}$ diffuses into the $\mathrm{Ni}$ phase, and as a consequence, the Ni-binder phase can be inferred to become a solid solution state dissolving more $\mathrm{Ti}$ than carbon. The free carbon did not disappear even if the compact was sintered above the eutectic temperature. However, the free carbon is detrimental to the strength of sintered compact, so that it must be eliminated.

\section{Effect of addition of molybdenum}

Methods for the elimination of the free carbon in the stage of diffusion-sintering and protection of $\mathrm{TiC}$ against the liquid in the stage of liquid phase-sintering werc examined. In this regard, the effect of addition of Mo was investigated. A $70 \%$ TiC-20\% Ni-10\% Mo compact was prepared and sintered under the same condition as that of the $70 \% \mathrm{TiC}-30 \% \mathrm{Ni}$ compact. As shown in Photo. 2, there appears a graphite-phase hardly observable microstructurally. This effect of addition of Mo may also be explained in the following way : $\mathrm{Mo}_{2} \mathrm{C}$ formed in the stage of diffusion-sintering is combines with $\mathrm{TiC}$ as a solid solution on the surface of the TiC particle at a higher temperature, whereby $\mathrm{TiC}$ particle would be protected against the liquid phase. (10)

Humenik et al.(11) has made a study of the effect of addition of Mo. According to them, the contact angle between binder-metal and $\mathrm{TiC}$ did not become zero when only $\mathrm{Ni}$ was used as a binder, but with the addition of $10 \mathrm{wt} \%$ Mo to the Ni-binder, the contact angle became zero. The addition of molybdenum would

(10) T. Fukatsu: To be published.

(11) M. Humenik and N. Parikh: J. Amer. Ceram. Soc., 39 (1956), 60. not only improve the wettability which is indespensable for the sintering 'process, but also play an important role in suppressing the formation of free carbon.

\section{Structure of the binder phase}

The amount of TiC dissoled in the Ni-binder phase

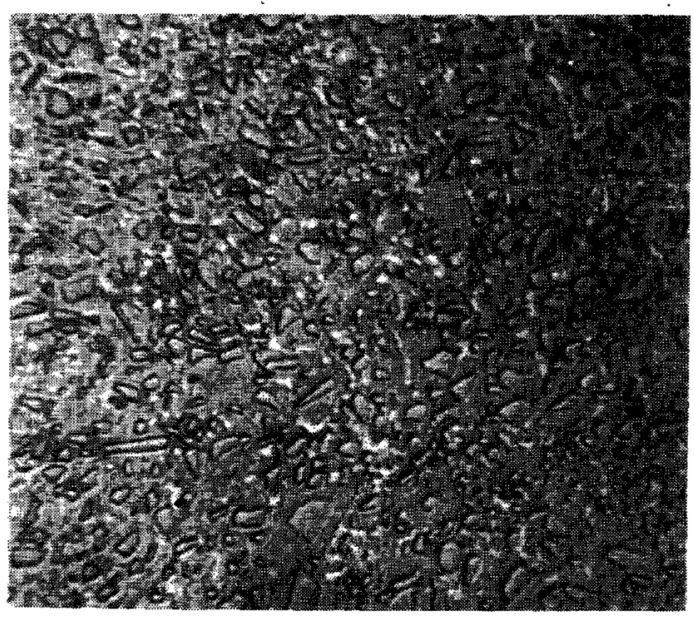

$(\times 1500)$

Photo. 2 Microstrectures of $70 \% \mathrm{TiC}-20 \% \mathrm{Ni}-10 \% \mathrm{Mo}$ compact sintered under the same condition as the specimen of Photo. 1 .

of the sintered compact can be estimated from the Curie temparature or the lattice-constant of Ni-TiC solid solution in the compact. The result obtained are plotted in Fig. 5 in which the notation of $\odot$ and $x$ represents the data of the Curie temperature and $\mathrm{X}$-ray

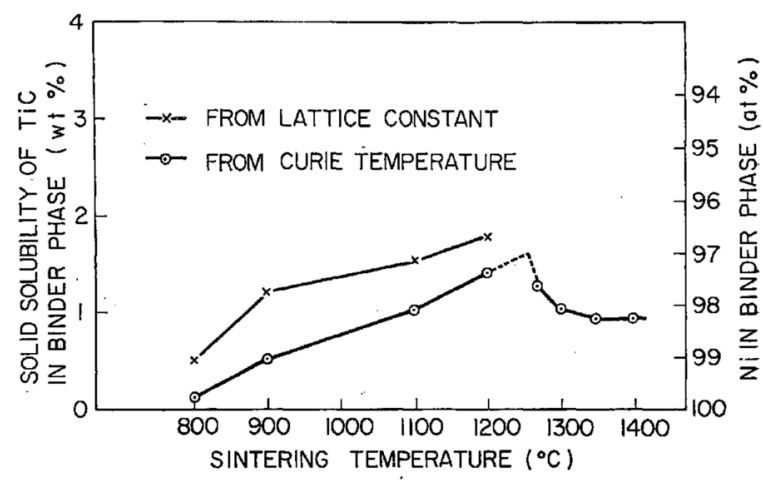

Fig. 5 Amounts of $\mathrm{TiC}$ dissloved in $\mathrm{Ni}$-binder phase.

analysis, respectively. In these curves, it is found that the amount of $\mathrm{TiC}$ in the $\mathrm{Ni}$ phase determined from the Curie temperature is smaller by about $0.5 \%$ than that from the lattice constant. This difference is probably due to the following two reasons: First, since the amount of free carbon in the compact increased during sintering as already noted, $\mathrm{Ni}$ did not dissolve $\mathrm{Ti}$ and $\mathrm{C}$ in equal amounts corresponding to the stoichiometric composition of TiC but a larger amount of $\mathrm{Ti}$ than C. For this reason, strictly speaking, it is not accurate to estimate the amount of $\mathrm{TiC}$ from the relationship shown in Fig. 1, and therefore the results shown in Fig. 5 are regarded as approximate values. Secondly; since the thermomagnetic curves in Fig. 3 deviate towards the lower side of the normal curve for a homogeneous ferromagnetic substance except the curve as pressed, the concentration of $\mathrm{TiC}$ in the $\mathrm{Ni}$ binder is not homogeneous. For the two reasons 
mentioned above, a lower estimaion was made for the amount of $\mathrm{TiC}$ from the Curie temperature. On the other hand, according to a study of the phase diagram of Ti-Ni-C by Stover et al. the solubility of $\mathrm{Ti}$ and $\mathrm{C}$ in the solid $\mathrm{Ni}$ phase is reported to be 3.2 at $\% \mathrm{Ti}$ and 1.2 at $\% \mathrm{C}$ at $1000^{\circ} \mathrm{C}, 3.4$ at $\% \mathrm{Ti}$ and 2.2 at $\% \mathrm{C}$ at $1200^{\circ} \mathrm{C}$ and 3.3 at $\% \mathrm{Ti}$ and 2.7 at $\% \mathrm{C}$ at $1260^{\circ} \mathrm{C}$. In view of the above values much larger than those in the present experiment, the diffusion of $\mathrm{TiC}$ into the $\mathrm{Ni}$ phase does not probably reach an equilibrium state.

The exact estimation of solubility of $\mathrm{TiC}$ in $\mathrm{Ni}$ remains a debatable question. However, from these results it seems that $\mathrm{TiC}$ diffuses into the Ni-binder phase during sintering below the eutectic temperature of $\mathrm{TiC}-\mathrm{Ni}$, and free carbtn is formed in relation to this diffusion. In pracice the rate of heating up to the eutectic temperature must be controlled strictly.

\section{Summary}

In order to study the structure and properties of the metal binder phase of sintered TiC-Ni compact, $\mathrm{Ni}$ solid solution containing $0 \sim 3.0 \mathrm{wt} \% \mathrm{TiC}$ were made, the lattice-constant and Curie temperature of which were measured as a function of the amount of $\mathrm{TiC}$ dissolved in the solid $\mathrm{Ni}$ phase. Based on these data, the binder phase of $\mathrm{TiC}-\mathrm{Ni}$ compacts sintered at various temperatures were investigated by means of X-ray diffraction and thermomagnetic analyses as well as chemical analysis of free carbon. The results obtained may be summarized as follows:

(1) The lattice constant of $\mathrm{Ni}-\mathrm{TiC}$ solid solution increases linearly at a rate of about $0.007 \AA /$ wt \% TiC and the Curie temperature decreases at a rate of about $55^{\circ} \mathrm{C} / \mathrm{wt} \% \mathrm{TiC}$ with the increasing amount of $\mathrm{TiC}$ in the sold $\mathrm{Ni}$ phase, respecitvely.

(2) In the sintering process, $\mathrm{TiC}$ begins to diffuse into Ni-binder at about $800^{\circ} \mathrm{C}$ its amount increases with increase of the sintering temperature up to the eutectic temperature. For example, the amount of $\mathrm{TiC}$ in the Ni phase of the compact sintered at $1200^{\circ} \mathrm{C}$ for $1 \mathrm{hr}$ was $1.5 \mathrm{wt} \%$. But it did not increase more than 1 wt $\%$ when the compacts were sintered above the eutectic temperature, $1270^{\circ} \mathrm{C}$.

(3) As a result of the diffusion of $\mathrm{TiC}$ into the $\mathrm{Ni}$ phase, free carbon was formed. The amount seems to increase as the amount of $\mathrm{TiC}$ dissolved increases. For exampe, the maximum amount of free carbon was evauated to be about $0.7 \mathrm{wt} \%$ in the specimen sintered at $1200^{\circ} \mathrm{C}$ for $1 \mathrm{hr}$ where the lowest Curie temperature was observed. But the amount of free carbon was evaluated $0.5 \mathrm{wt} \%$ in the specimens sintered above the eutectic temperature.

(4) Such free carbon formed appears in the binder phase of the TiC-Ni compact as a graphite phase, but it can be eliminated by the addition of molybdenum.

The authors wish to thank Dr. K. Iwase, Professor S. Kachi of Kyoto Univ., Dr. T. Takada of Kyoto Univ., and Mr. S. Yamaya of the authors' company. 